\title{
Discovery and implementation of a novel pathway for $n$-butanol production via 2-oxoglutarate
}

\author{
Sofia Ferreira ${ }^{1}$, Rui Pereira ${ }^{2,3}$, Filipe Liu ${ }^{1,4}$, Paulo Vilaça ${ }^{2}$ and Isabel Rocha ${ }^{1,5^{*}}$ (i)
}

\begin{abstract}
Background: One of the European Union directives indicates that 10\% of all fuels must be bio-synthesized by 2020. In this regard, biobutanol—natively produced by clostridial strains_-poses as a promising alternative biofuel. One possible approach to overcome the difficulties of the industrial exploration of the native producers is the expression of more suitable pathways in robust microorganisms such as Escherichia coli. The enumeration of novel pathways is a powerful tool, allowing to identify non-obvious combinations of enzymes to produce a target compound.

Results: This work describes the in silico driven design of E. coli strains able to produce butanol via 2-oxoglutarate by a novel pathway. This butanol pathway was generated by a hypergraph algorithm and selected from an initial set of 105,954 different routes by successively applying different filters, such as stoichiometric feasibility, size and novelty. The implementation of this pathway involved seven catalytic steps and required the insertion of nine heterologous genes from various sources in E. coli distributed in three plasmids. Expressing butanol genes in E. coli K12 and cultivation in High-Density Medium formulation seem to favor butanol accumulation via the 2-oxoglutarate pathway. The maximum butanol titer obtained was $85 \pm 1 \mathrm{mg} \mathrm{L}^{-1}$ by cultivating the cells in bioreactors.

Conclusions: In this work, we were able to successfully translate the computational analysis into in vivo applications, designing novel strains of $E$. coli able to produce $n$-butanol via an innovative pathway. Our results demonstrate that enumeration algorithms can broad the spectrum of butanol producing pathways. This validation encourages further research to other target compounds.
\end{abstract}

Keywords: $n$-Butanol, E. coli, Metabolic engineering, Enumeration algorithms, 2-Oxoglutarate

\section{Background}

Butanol poses as a promising alternative to ethanol as a fuel due to its superior properties, such as higher energy content, less corrosiveness and higher blending capacity with gasoline [1]. $\mathrm{N}$-Butanol is natively produced together with ethanol and acetone through acetonebutanol-ethanol (ABE) fermentation by Clostridium species [2,3]. Engineering its native host to improve butanol production is often complicated by, among other factors, the difficulty in performing genetic manipulations

\footnotetext{
*Correspondence: irocha@itqb.unl.pt

${ }^{5}$ Instituto de Tecnologia Química e Biológica António Xavier,

Universidade Nova de Lisboa (ITQB-NOVA), Oeiras, Portugal

Full list of author information is available at the end of the article
}

in Clostridium spp. and the formation of spores during butanol production in the solventogenic phase.

The expression of Clostridia butanol pathway in a more robust microbial host, such as Escherichia coli was firstly implemented by the Atsumi et al. in 2008 [4]. Nevertheless, the low butanol titers obtained with $E$. coli show that many challenges remain in turning this organism into a viable butanol production host. For example, the first reaction of the clostridial pathway-the condensation of two molecules of acetyl-CoA into one molecule of acetoacetyl-CoA-is thermodynamically unfavorable [5]. Also, other enzymes of this pathway appear to be poorly expressed in E. coli, such as butyryl-CoA dehydrogenase, the enzyme that catalyzes the reduction of butanoyl-CoA into crotonoyl-CoA [6]. Finally, the high requirement of 
reducing power and the consequent competition with native fermentation pathways have also to be considered when optimizing butanol production in heterologous hosts [7]. Several rational strategies were tested in E. coli to increase butanol productivity, especially metabolic engineering approaches such as manipulation of central carbon metabolism, elimination of competing pathways, gene overexpression, cofactor balancing, expression of novel enzymes and consumption of different substrates [8].

A strategy to tackle some of the issues arisen from expressing clostridial enzymes is to identify alternative butanol biosynthetic pathways more suitable for expression in standard microbial production hosts. Until now, only three alternative pathways for producing butanol have been tested in E. coli, besides the clostridial one. One explores the keto-acids metabolism [9] and the other two explore an engineered version of the $\beta$-oxidation pathway present in $E$. coli $[10,11]$. Regarding other microorganisms, a pathway converting malonyl-CoA into butanol in cyanobacteria was also reported [12].

Shen and Liao took advantage of the native amino acid pathway overcoming the need to involve CoA-dependent intermediates and producing simultaneously butanol and propanol [9]. In their work, E. coli was engineered to increase the pool of 2-ketobutyrate, a common keto-acid intermediate in isoleucine biosynthesis, later converted into butanol through the norvaline biosynthetic pathway.

Dellomonaco and coworkers engineered E. coli to activate the reverse $\beta$-oxidation cycle in the absence of the inducing substrate (fatty acids) [10]. The constitutive expression of this pathway was achieved by introducing mutations in the corresponding transcriptional regulators ( $f a d$, ato and $c r p)$ and knocking out $\operatorname{arcA}$. In a similar approach, Debabov et al. also explored the reversed $\beta$-oxidation pathway, but only expressing enzymes from this pathway and an aerotolerant mutant $a d h E$ to convert butyryl-CoA into butanol [11].

In this work, we used a previously optimized hypergraph algorithm [13] to enumerate all possible pathways leading from $E$. coli's metabolism to butanol. The pathways were analyzed to infer their feasibility to be applied in vivo. First, the solutions were evaluated according to diverse criteria (butanol yield, number of reactions and novelty) to seek the most promising solutions. For each of the steps composing the novel pathway, enzymes were selected considering curated gene sequences and the experimental data available in the literature. Here, novel strains of E. coli producing butanol through a novel pathway were developed. The resulting set of genes catalyzing the successive reactions from 2-oxoglutarate to butanol originates from diverse microorganisms.

\section{Results}

Computational analysis and manual curation of heterologous pathways

The set of heterologous pathways generated using our methodology described in [13] included 105,954 alternatives. After discarding all the pathways that could not carry flux into the target product (butanol), only 40,608 different pathways were left. Since the clostridial butanol pathway possesses 6 heterologous reactions, a competing alternative should not be much larger. Therefore, the dataset was filtered to include only pathways with a maximum of 7 heterologous reactions. The application of this filter resulted in 316 pathways, which, in their turn, were ranked by size: 4 pathways with size equal to three reactions; 4 pathways with size equal to four reactions; 120 pathways with size equal to six reactions and 188 pathways with size equal to seven reactions. Since a higher number of catalytic steps do not always translate into a higher number of expressed proteins, we have also checked pathways with more than seven catalytic steps. The group of pathways larger than 7 steps included more complex variations of the shorter pathways and were discarded. The precursors of these vias were $E$. coli metabolites more distant from the central carbon and thus required the expression of more heterologous enzymes to be implemented in vivo than the shorter alternatives.

After reviewing the literature to infer their novelty, 24 pathways, all constituted by seven catalytic steps, have remained and considered the most auspicious for further analysis and in vivo implementation. Figure 1 depicts the various stages of the in silico analysis from the initial set of pathways, as well as a representation of the final set of pathways using 2-oxoglutarate as the main precursor.

In this set of pathways, first 2-oxoglutarate is reduced to 2-hydroxyglutarate via reaction R08198 or R03534 (all reaction identifiers are from KEGG [14-16]). Then, in reaction R04000, Coenzyme A is transferred from acetylCoA (releasing acetate) to 2-hydroxyglutarate forming 2-hydroxyglutaryl-CoA, followed by its dehydration into glutaconyl-CoA (reaction R03937). In the next reaction (R03028), glutaconyl-CoA is decarboxylated into crotonyl-CoA. The remaining reactions are common to clostridial pathway. Three different alternatives (R01171; R01175 and R09738) have been enumerated for the reduction of crotonyl-CoA in butanoyl-CoA. The last two steps are the successive reductions of butanoyl-CoA to butanal (R01173 or R01172) and of butanal to $n$-butanol (R03544 and R03545).

Although the main intermediary metabolites are common to all pathways present in the final set, the number of alternative routes [24] is a consequence of four out of the seven enzymatic steps allowing the use of different cofactors. The main novelty of this set of 24 pathways 


\section{Pathways generated by a hypergraph algorithm}

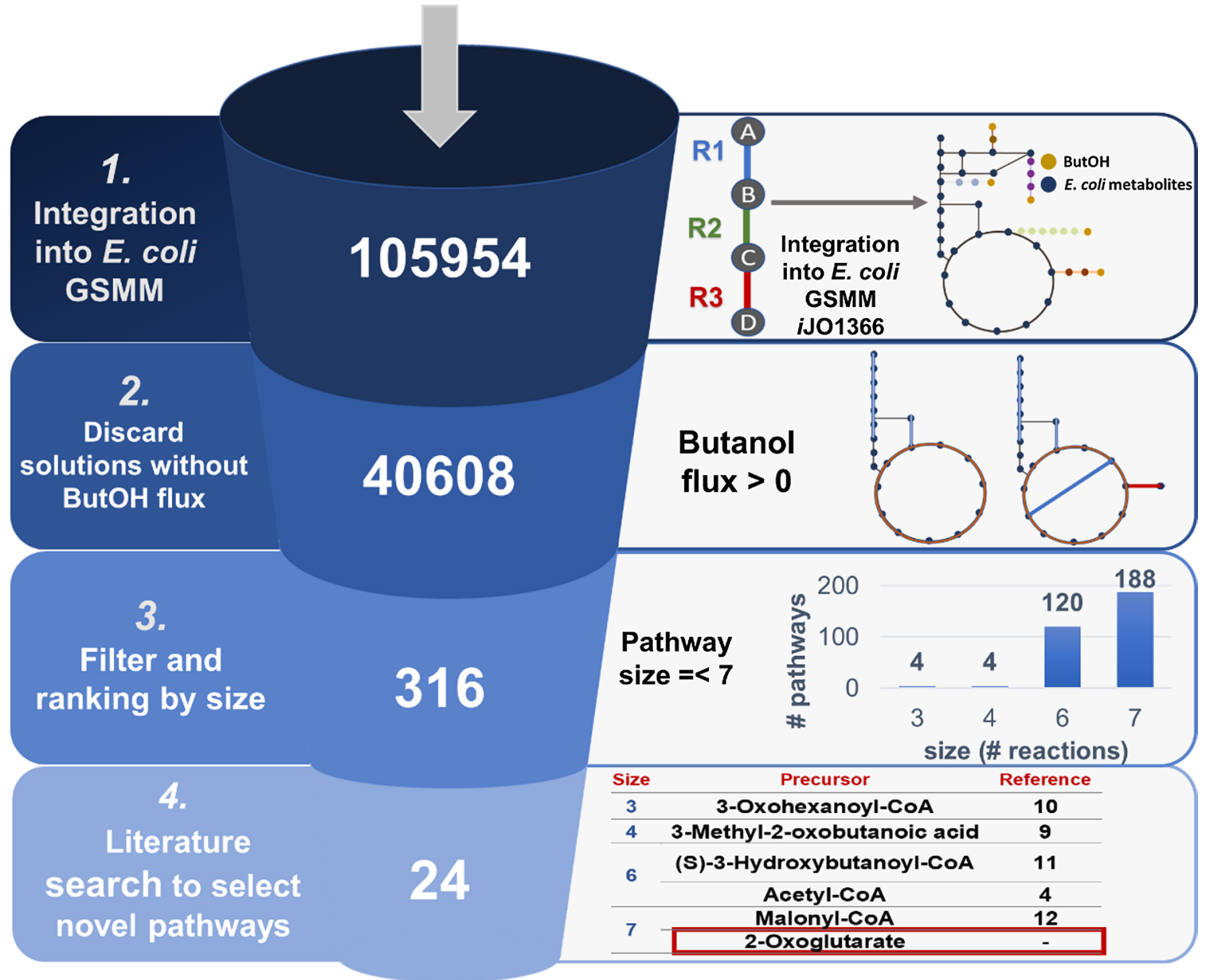

Set of promising pathways to apply in vivo<smiles>O=C(O)CCC(=O)C(=O)O</smiles>

2-Oxoglutarate

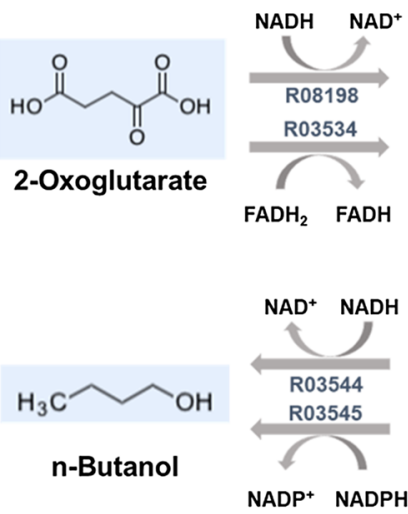

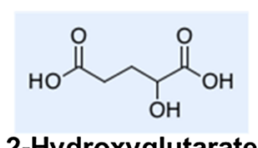

2-Hydroxyglutarate

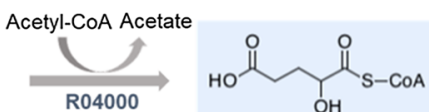

2-Hydroxyglutaryl-CoA

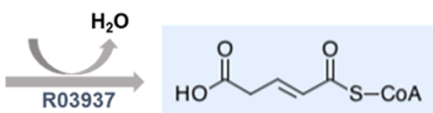

Glutaconyl-CoA

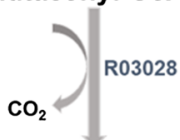<smiles>CCCC=O</smiles>

Butanal

$$
\text { COA }
$$

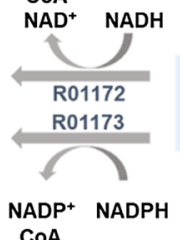
CoA

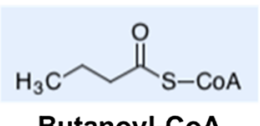

Butanoyl-CoA

Fig. 1 Schematic representation of the successive stages of the in silico analysis. The pathways to produce butanol in E. coli were generated using the algorithms described in [13], were filtered and ranked, resulting in a set of the 24 most promising alternatives. The reactions constituting the final set of pathways are shown with indication of the respective KEGG ID. These pathways are constituted by the following enzymatic activities: 2-oxoglutarate reductase (R08198 and R03534); glutaconate-CoA transferase (R04000); 2-hydroxyglutaryl-CoA dehydratase (R03937); glutaconyl-CoA decarboxylase (R03028); butyryl-CoA dehydrogenase (R01171; R01175 and R09738); aldehyde dehydrogenase (R01172 and R01173) and alcohol dehydrogenase (R03544 and R03545). GSMM genome-scale metabolic model, ButOH butanol 
concerns the use of 2-oxoglutarate as the main precursor. 2-Oxoglutarate is a keto-acid that is an intermediate in TCA cycle and can be formed from the oxidation of isocitrate and subsequent decarboxylation of the intermediate oxalosuccinate. In anaerobic conditions, producing butanol from 2-oxoglutarate has a maximum theoretical yield similar to the clostridial and ketoacids pathways (clostridial and ketoacids: $0.41 \mathrm{~g} \mathrm{~g}^{-1}$; 2OG: $0.40 \mathrm{~g} \mathrm{~g}^{-1}$ ). The main difference between the two pathways is the amount of ATP that is produced in fermentative conditions with butanol as main product. Producing butanol using the 2OG pathway requires the carboxylation of one phosphoenolpyruvate molecule to oxaloacetate and the activation of 2-hydroxyglutarate to 2-hydroxyglutarylCoA using acetyl-CoA as a donor. These steps require extra energy input in comparison to the clostridial pathway, which makes the $2 \mathrm{OG}$ pathway less advantageous in this regard. Although the amount of ATP generated is lower, the $2 \mathrm{OG}$ pathway compensates in terms of thermodynamic feasibility (see "Pathway feasibility evaluation"). To the best of our knowledge, this set of pathways has not been reported in the literature and, for this reason, was selected for further analysis.

Some of the catalytic steps constituting the proposed pathway can be catalyzed using alternative cofactors $\left(\mathrm{NADH}\right.$ or NADPH/FADH ${ }_{2}$ ). To infer what is the best combination of cofactors to produce butanol in $E$. coli, all reactions were added to the $E$. coli genomescale metabolic model (GSMM) iJO1366, under anaerobic conditions, with glucose uptake rate equal to $10 \mathrm{mmol}\left(\mathrm{g}_{\mathrm{DW}} \mathrm{h}\right)^{-1}$. Butanol flux was then maximized to infer which reactions were active. As expected, in conditions favoring an excess of $\mathrm{NADH}$, all the reactions recycling $\mathrm{NADH}$ had flux through butanol production and the remaining ones were inactive (Additional file 1: Table S1).

Thus, the pathway selected for further analysis utilizes only $\mathrm{NADH}$ as the donor of reducing power and was named pathway $2 \mathrm{OG}$.

\section{Pathway feasibility evaluation}

Since the KEGG database lacks information regarding directionality, all reactions are reversible by default. Therefore, it was necessary to check if each reaction in $2 \mathrm{OG}$ pathway occurs in the desired direction towards butanol; or if it is more likely to happen in the opposite way. The change in Gibbs Energy $\left(\Delta_{r} G\right)$ is a practical indicator for reaction directionality: a reaction will be favorable in a certain direction if $\Delta_{r} G$ is negative, meaning Gibbs energy decreases during a reaction as ruled by the second law of thermodynamics [17]. For this reason, we calculated $\Delta_{r} G^{\prime m}$, the change in Gibbs energy, considering reactants concentrations of $1 \mathrm{mM}$, a realistic concentration range at the cell context [18] using eQuilibrator [17]. Furthermore, to implement this pathway in vivo, we searched for possible genes coding for each of the required enzymatic activities. For each reaction active during the computational simulation (Additional file 1: Table S1), the estimated $\Delta_{r} G^{\prime m}$ and respective gene sequences are shown in Table 1.

As shown in Table 1, the estimated $\Delta_{r} G^{\prime m}$ values were negative for all reactions with exception of the third step (R03937), the dehydration of 2-hydroxyglutaryl-CoA into glutaconyl-CoA. In this case, the estimated $\Delta_{r} G^{\prime m}$ value was close to $0\left(0.7 \pm 2.9 \mathrm{~kJ} \mathrm{~mol}^{-1}\right)$, indicating that probably the reaction is reversible. Although a value of $\Delta_{r} G^{\prime m}$ close to zero suggests that neither direction is favored, in physiological conditions, the flux can still be forced in the forward direction by increasing the concentration of 2-hydroxyglutatyl-CoA sufficiently above the concentration of the products [18]. The subsequent step (R03028) is much more favored in the forward direction with a $\Delta_{r} G^{\prime m}$ of $-35.8 \pm 17.4 \mathrm{~kJ} \mathrm{~mol}^{-1}$ and $K_{\text {eq }}^{\prime} 1.9 \times 10^{3}$. So, we expect that this reaction will ensure the depletion of glutaconyl$\mathrm{CoA}$ and drive the flux of the previous reaction in the desired direction. Regarding the other reactions of this pathway, the negative values of $\Delta_{r} G^{\prime m}$ suggest that the production of butanol from 2-oxoglutarate is thermodynamically favorable.

After analyzing the literature, it was possible to conclude that all the catalytic steps constituting the proposed pathway have gene sequences available and experimental validation for the substrate. The first four reactions of the proposed pathway in Fig. 1 are part of the glutamate fermentation via the (R)-2-hydroxyglutarate pathway. This pathway, firstly described in 1974 [34], is present in different bacteria; the best known is the strictly anaerobic gut bacterium Acidaminococcus fermentans [34]. Moreover, the gene sequences selected for steps 1-3 were already validated for glutaconate production in $E$. coli [20].

The last steps of the pathway from crotonyl-CoA to butanol are common to clostridial pathway. For this reason, different enzymes catalyzing these reactions have been tested in E. coli. Regarding the reduction of crotonyl-CoA into butyryl-CoA, the expression of the clostridial butyryl-CoA dehydrogenase (Bcd-EtfAB) in $E$. coli is challenging due to its oxygen sensitivity and the requirement of ferredoxin as the electron donor [5, 35]. It was shown that another class of enzymes (transenoyl-reductases) also catalyzes this reaction increasing butanol titers when replacing the complex $b c d$-etfAB [5]. Thus, the protein product of ter from Treponema denticola was selected.

The two successive reductions of butyryl-CoA into butyraldehyde and to butanol are catalyzed by the 
Table 1 Estimated change in Gibbs energy and experimental validation for the reactions constituting the 2-oxoglutarate pathway

\begin{tabular}{|c|c|c|c|c|c|c|c|c|}
\hline Step & Reaction & $\begin{array}{l}\Delta_{r} G^{\prime m} \\
\left(\mathrm{KJ} \mathrm{mol}^{-1}\right)\end{array}$ & $K_{\text {eq }}^{\prime}$ & E.C. number & Enzyme & $\begin{array}{l}\text { Gene } \mathrm{NCBI} \\
\text { accession no }\end{array}$ & $\begin{array}{l}\text { Enzymatic } \\
\text { activity }^{\mathrm{a}}\end{array}$ & $\begin{array}{l}\text { Exp. } \\
\text { validation } \\
\text { in E. coli }\end{array}$ \\
\hline 1 & $\begin{array}{l}\text { 2-Oxoglutarate }+\mathrm{NADH}+\mathrm{H}^{+} \Longleftrightarrow 2 \text {-Hydrox- } \\
\text { yglutarate }{ }^{\mathrm{b}}+\mathrm{NAD}^{+}\end{array}$ & $-22.6 \pm 3.6$ & $9.2 \times 10^{3}$ & EC 1.1.1.399 & $\begin{array}{l}\text { 2-Oxoglutarate } \\
\text { reductase }\end{array}$ & $\begin{array}{l}\text { hgdH [AF] } \\
\text { WP_012938338 }\end{array}$ & [19] & {$[20,21]$} \\
\hline 2 & $\begin{array}{l}\text { Acetyl-CoA }+2 \text {-Hydroxyglutarate } \Longleftrightarrow \text { Ace- } \\
\text { tate }+2 \text {-Hydroxyglutaryl-CoA }\end{array}$ & $-8.6 \pm 15.3$ & 32.1 & EC 2.8.3.12 & $\begin{array}{l}\text { Glutaconate } \\
\text { CoA- } \\
\text { transferase } \\
\text { (subunits a } \\
\text { and } \beta \text { ) }\end{array}$ & $\begin{array}{l}\text { gctA [AF] } \\
\text { WP_012939156.1 } \\
\text { gctB [AF] } \\
\text { WP_012939155.1 }\end{array}$ & {$[22]$} & \\
\hline \multirow[t]{2}{*}{3} & \multirow[t]{2}{*}{$\begin{array}{l}\text { 2-Hydroxyglutaryl-CoA } \Longleftrightarrow \text { Glutaconyl- } \\
\qquad \mathrm{CoA}+\mathrm{H}_{2} \mathrm{O}\end{array}$} & \multirow[t]{2}{*}{$0.7 \pm 2.9$} & \multirow[t]{2}{*}{0.751} & \multirow[t]{2}{*}{ EC 4.2.1.167 } & \multirow[t]{2}{*}{$\begin{array}{l}\text { (R)-2-Hydroxy- } \\
\text { glutaryl-CoA } \\
\text { dehydratase } \\
\text { Subunits a, } \beta \\
\text { and activator }\end{array}$} & $\begin{array}{l}\text { hgdA [CS] } \\
\text { WP_003501726.1 } \\
\text { hgdB [CS] } \\
\text { WP_003501727.1 }\end{array}$ & {$[23]$} & \\
\hline & & & & & & $\begin{array}{l}\text { hgdC [AF] } \\
\text { WP_012939153.1 }\end{array}$ & {$[24]$} & \\
\hline \multirow[t]{2}{*}{4} & \multirow[t]{2}{*}{ Glutaconyl-CoA $\Longleftrightarrow$ Crotonyl-CoA $+\mathrm{CO}_{2}$} & \multirow[t]{2}{*}{$-35.8 \pm 17.4$} & \multirow[t]{2}{*}{$1.9 \times 10^{3}$} & EC 1.3.8.6 & $\begin{array}{l}\text { Glutaryl-CoA } \\
\text { dehydroge- } \\
\text { nase }\end{array}$ & $\begin{array}{l}\text { gcdH [PA] } \\
\text { WP_042912665.1 }\end{array}$ & {$[25]$} & - \\
\hline & & & & EC 4.1.1.70 & $\begin{array}{l}\text { Glutaconyl- } \\
\text { CoA decar- } \\
\text { boxylase a } \\
\text { subunit }\end{array}$ & $\begin{array}{l}\operatorname{gcd} A[C S] \\
\text { WP_003501720.1 }\end{array}$ & {$[26]$} & - \\
\hline 5 & $\begin{array}{l}\text { Crotonyl-CoA }+\mathrm{NADH}+\mathrm{H}^{+} \Longleftrightarrow \text { Butanoyl- } \\
\mathrm{CoA}+\mathrm{NAD}^{+}\end{array}$ & $-40.0 \pm 17.0$ & $1.0 \times 10^{7}$ & EC 1.3.1.44 & $\begin{array}{l}\text { Trans-2- } \\
\text { enoyl-CoA } \\
\text { reductase }\end{array}$ & $\begin{array}{l}\operatorname{ter}[\mathrm{TD}] \\
\text { WP_002681770.1 }\end{array}$ & {$[27]$} & {$[5,28-30]$} \\
\hline 6 & $\begin{array}{l}\text { Butanoyl-CoA + NADH }+\mathrm{H}^{+} \Longleftrightarrow \text { Buta- } \\
\quad \text { nal }+\mathrm{CoA}+\mathrm{NAD}^{+}\end{array}$ & $-57.0 \pm 16$ & $9.6 \times 10^{9}$ & EC 1.2.1.57 & $\begin{array}{l}\text { Aldehyde/ } \\
\text { alcohol }\end{array}$ & $\begin{array}{l}\text { adhE1 [CA] } \\
\text { WP_077851567.1 }\end{array}$ & {$[31]$} & {$[32,33]$} \\
\hline 7 & Butanal $+\mathrm{NADH}+\mathrm{H}^{+} \Longleftrightarrow$ Butanol $+\mathrm{NAD}^{+}$ & $-24.2 \pm 4.8$ & $1.8 \times 10^{4}$ & EC 1.1.1.1 & $\begin{array}{l}\text { dehydroge- } \\
\text { nase }\end{array}$ & & & \\
\hline
\end{tabular}

The estimated change in Gibbs free energy $\left(\Delta_{r} G^{\prime m}\right)$ values were computed with eQuilibrator [17] for each reaction constituting the novel pathway to produce butanol from 2-oxoglutarate (assumptions: reactant/product concentrations of $1 \mathrm{mM}$ ), as well as equilibrium constant $\left(K_{\text {eq }}^{\prime}\right)$ values at a pH of 7 and an ionic strength of $0.1 \mathrm{M}$. The encoding gene and respective microorganism, as well as references of enzymatic activity validation with the substrate and experimental validation in Escherichia coli are also shown, plus the EC number and NCBI accession number

Exp experimental, EC enzyme commission, AF Acidaminococcus fermentans, CS Clostridium symbiosum, PA Pseudomonas aeruginosa, TD Treponema denticola, CA Clostridium acetobutylicum

a This refers to the substrate in italics in the reaction column

b Only the enzymes converting the (R)-isomer were considered. There are two enantiomers of 2-hydroxyglutarate; however, in KEGG (the database from which the reactions were retrieved), these variations are not represented. Depending on the enzyme, one of these forms can be preferably synthesized. The two subsequent reactions are part of the glutamate degradation pathway, existent is some microorganisms, where the (R)-isomers of the other compounds are preferably consumed

bifunctional aldehyde/alcohol dehydrogenase. For these two last steps, the gene $a d h E 1$ was selected since it was already validated for butanol production [32].

The main unknown regarding the novel butanol production pathway depicted in Fig. 1 concerns the decarboxylation of glutaconyl-CoA into crotonyl-CoA. This step is of increased importance because it is at the intersection between the upstream reactions-already experimentally validated for the production of glutaconate in E. coli [20]-and the downstream reactions, validated for the production of butanol [5] as shown in Table 1. Two genes were found to encode enzymes catalyzing this enzymatic step, but neither gave us enough confidence to apply directly in vivo because their activity was not previously validated in $E$. coli. The decarboxylation of glutaconyl-CoA into crotonyl-CoA can be catalyzed directly by glutaconyl-CoA decarboxylase [26], or, as an intermediate step, by glutaryl-CoA dehydrogenase [25]. For this reason, two different constructions were designed to test these two different enzymes for this particular step.

Glutaryl-CoA dehydrogenase is a bifunctional enzyme that catalyzes the decarboxylation of glutaconyl-CoA into crotonyl-CoA, using glutaryl-CoA as the initial substrate and glutaconyl-CoA as an intermediate [36]. Enzymatic assays showed that this enzyme was able to catalyze directly the conversion of glutaconyl-CoA into crotonylCoA with an activity 1.2-1.6 times higher than for the first step [25]. This enzyme was identified in cell-free extracts of Pseudomonas sp when grown anaerobically 


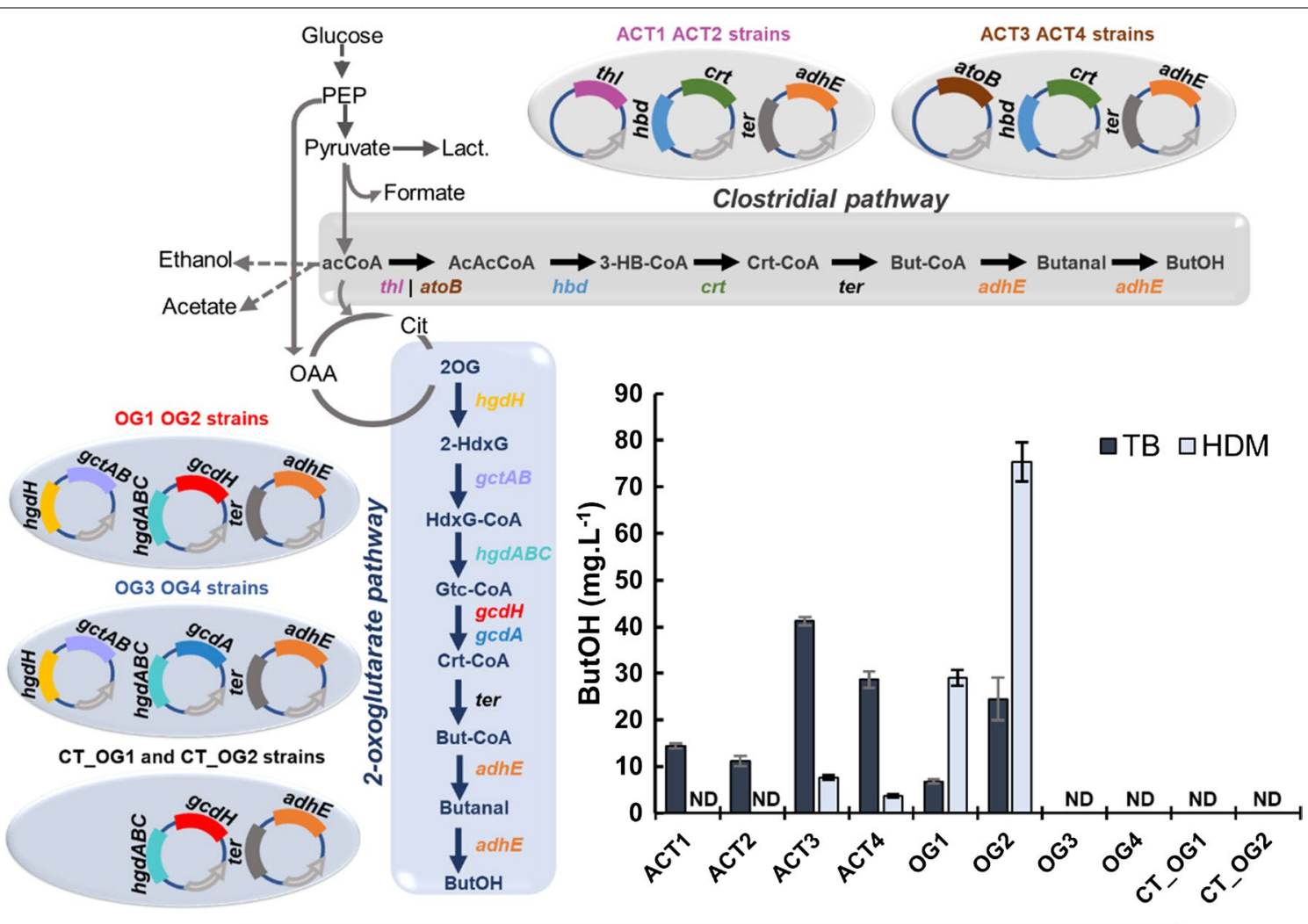

Strains 1 and 3: Escherichia coli BL21 (De3) based cells

Strains 2 and 4: Escherichia coli K12 (De3) based cells

Fig. 2 Butanol titer $\left(\mathrm{mg} \mathrm{L}^{-1}\right)$ for the different strain designs in TB medium and HDM medium. The different enzymes expressed in each strain are indicated. In all experiments, strains were grown in shake flasks until reaching $0.4-0.5 \mathrm{OD}_{600} .0 .5 \mathrm{mM}$ of IPTG was then added to the medium and cells transferred to sealed serum bottles. Data are shown as mean \pm SD from three independent experiments. ND not detected; the detection limit of the method is $3 \mathrm{mg} \mathrm{L}^{-1}$. 2OG 2-oxoglutarate, 2-HdxG 2-hydroxyglutarate, HdxG-COA 2-hydroxyglutaryl-CoA, Gtc-COA glutaconyl-CoA, Crt-CoA crotonyl-CoA, But-CoA butanoyl-CoA, ButOH butanol, acCoA ACETYL-CoA, ACAcCoA acetoacetyl-CoA, 3-HB-CoA 3-hydroxybutyryl-CoA, Cit citrate, Lact lactate, OAA oxaloacetate, PEP phosphoenolpyruvate

in aromatic compounds [25]. A curated gene sequence encoding this enzyme was available for Pseudomonas aeruginosa PAO1.

Glutaconyl-CoA decarboxylase is a four-subunit membrane-bound enzyme that catalyzes the conversion of glutaconyl-CoA into crotonyl-CoA, working as a biotindependent sodium pump [37]. This enzyme is involved in the fermentation of glutamate by strictly anaerobic bacteria. Glutaconyl-CoA decarboxylases from the bacteria Acidaminococcus fermentans [38] and Clostridium symbiosum [26] were crystalized and characterized. Considering that the butanol production pathway tested here requires a high number of heterologous genes, we decided to express only the $\alpha$-subunit of the glutaconylCoA decarboxylase (encoded by $\operatorname{gcd} A$ ), which is able to catalyze the reaction as long as biotin is also supplied. Regarding the microorganism source, within the best studied glutaconyl-CoA decarboxylases, we have selected
Clostridium symbiosum because the $K_{m}$ for biotin was 14-times lower than the value obtained for the $\alpha$-subunit of glutaconyl-CoA decarboxylase from A. fermentans [26].

\section{In vivo implementation}

Two different constructions were designed with all the genes constituting the pathway and two different enzymes for the fourth step: one expressing a glutarylCoA dehydrogenase $(g c d H)$ from Pseudomonas aeruginosa and another one expressing the $\alpha$-subunit of glutaconyl-CoA decarboxylase $(g c d A)$ from C. symbiosum. These genes were introduced in BL21 (De3) (OG1 and OG3)- and K-12-based cells (OG2 and OG4) as depicted in Fig. 2. The developed strains were cultivated in the complex medium TB and in the synthetic HDM medium, induced with 0.5 of IPTG and immediately 
switched to sealed serum bottles. The results are summarized in Fig. 2.

The butanol titers obtained by testing the fours strains expressing the 2OG pathway showed that this compound could only be detected in strains where glutaryl-CoA dehydrogenase (OG1 and OG2) was expressed (detection limit is $\left.3 \mathrm{mg} \mathrm{L}^{-1}\right)$. Data retrieved from the literature showed that the sole expression of the $\alpha$-subunit of glutaconyl-CoA decarboxylase has a $V_{\max } 1000$ times lower than the full enzyme [26]. Therefore, it is not possible to affirm that this enzyme is not a viable option for the proposed pathway. Moreover, there is a discrepancy in the copy number of the plasmid used for expressing the two enzymes: pCOLADuet possesses 20-40 copy number per cell (plasmid used for $g c d A$ ), while pRSFDuet (the plasmid used to express $g c d H$ ) has a copy number higher than 100 plasmids per cells. To confirm that $g c d H$ is more suitable for this pathway, both genes should be cloned using the same conditions. Given the lack of butanol production in the strains expressing $g c d A$ and the challenge of expressing all four subunits of the transmembrane glutaconyl-CoA decarboxylase, further experiments with this pathway were performed only for the strains using the glutaryl-CoA dehydrogenase.

As depicted in Fig. 2, we implemented a few variations of the clostridial pathway in E. coli and compared with the 2OG pathway in terms of butanol production using the same culture conditions. For the first step of this route-the thermodynamically unfavorable condensation of two molecules of acetyl-CoA into one of acetoacetyl-CoA-two enzymes were tested: the protein products of the clostridial thl and of the E. coli native atoB. Both derivative pathways were expressed in BL21 (ACT1 and ACT3) and in K12 cells (ACT2 and ACT4). Butanol accumulation was detected in both designs either expressing thl or atoB. In accordance to the data previously reported, the cells expressing atoB (ACT3 and ACT4) achieved higher butanol titers than the ones expressing thl (ACT1 and ACT2) [9].

The maximum butanol titer obtained in serum bottles ( $75 \pm 4 \mathrm{mg} \mathrm{L}^{-1}$ ) was achieved by cultivating OG2 (E. coli $\mathrm{K} 12$ host) in HDM medium. This value is 1.8 -fold greater than the maximum butanol production obtained for the ACT strains $\left(41 \pm 8 \mathrm{mg} \mathrm{L}^{-1}\right)$, presenting a good indicator of the potential of this novel pathway.

For both OG1 and OG2 strains, HDM formulation seems to favor butanol production over TB medium. Contrarily, strains expressing clostridial pathway (ACT) achieved higher butanol titers in TB medium. Other publications have demonstrated that the presence in the medium of complex nutrients is beneficial for butanol production through the clostridial pathway and its derivatives. By removing complex nutrients such as tryptone and yeast extract from the medium, the authors observed a reduction in butanol production $[5,30]$. The contrasting behavior between the two butanol production pathways is likely to be a consequence of the different precursors used by each pathway and the influence of the complex nutrients on their availability.

To determine if the medium formulation used here could be further optimized, we omitted some of the extra components added in the synthetic medium formulation (HDM) (Additional file 2: Fig. S1). The formulation that provided the highest butanol titer for OG2 was the one including all the supplements. Surprisingly, for OG1, the omission of iron (III) citrate and riboflavin had a positive impact in the final butanol titer, representing a 1.5fold improvement when compared with the complete formulation of HDM. Iron(III) citrate and riboflavin were supplemented due to the reported requirements of 2-hydroxyglutarate dehydratase (encoded by the genes $h g d A B C)$ [20]. Given the direct connection between butanol production in the strains tested and 2OG, we expected that the omission of glutamate would cause the greatest impact on butanol titer. However, the results actually showed that omitting the mixture of amino acids resulted in a lower butanol accumulation than the single omission of glutamate.

Regarding the host strain used for butanol production, we observed that BL21 strains provided the highest butanol titers when expressing clostridial pathway and K12 based strains showed increased butanol production through the $2 \mathrm{OG}$ pathway.

To validate that the pathway introduced into $E$. coli was using 2-oxoglutarate as starting precursor, strains expressing only a part of the pathway, CT_OG1 and CT_OG2, were cultured in the same fashion as described before for experiments using TB and HDM media. These strains only expressed the final five catalytic steps of the pathway. The main goal was to infer if some alternative precursors were being used directly from the media by the enzymes catalyzing the final five reactions of the proposed pathway. Since butanol was not detected in all the performed experiments, we can conclude that all the three plasmids are needed to produce a detectable amount of butanol.

\section{Butanol production in bioreactors}

Under anaerobic conditions, E. coli produces mixed-acid fermentation products decreasing the $\mathrm{pH}$ of the medium, which can slow, or even stop growth. For this reason, OG2 (the strain that provided the greatest titers in the serum bottle experiments-Fig. 2) was cultivated under controlled conditions in a bioreactor.

OG2 was cultivated with 0.5 - $\mathrm{L}$ working volume in a 2-L bioreactor using HDM medium. Samples were taken 


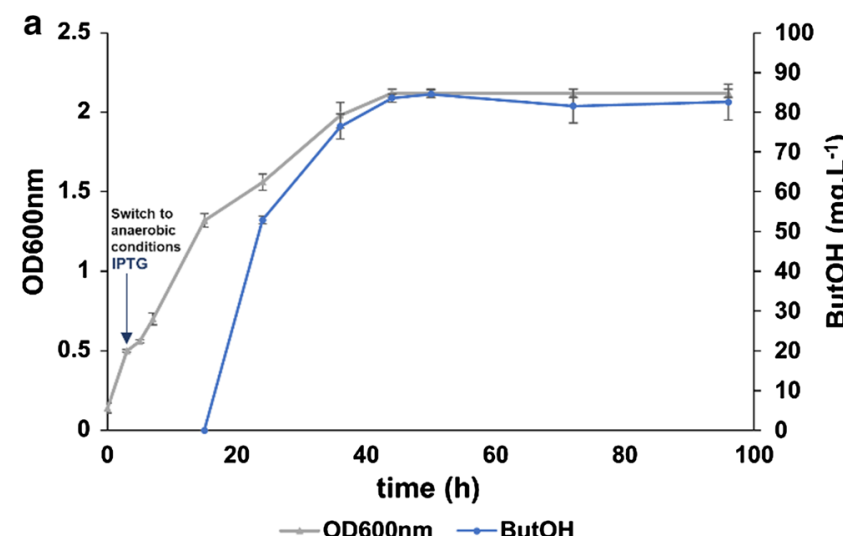

C

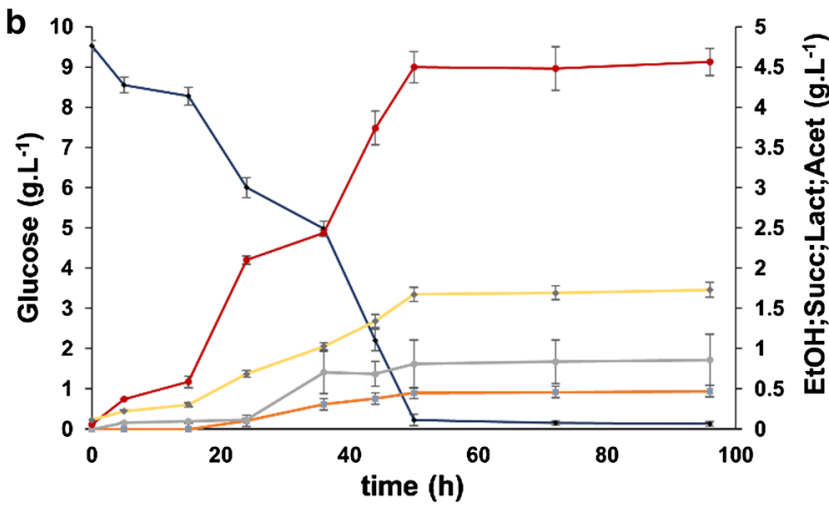

\begin{tabular}{cc}
\hline Parameter & Value \\
\hline $\boldsymbol{\mu}\left(\mathrm{h}^{-1}\right)$ & $0.035 \pm 0.002$ \\
\hline $\mathbf{t}_{\mathrm{d}}(\mathrm{h})$ & $19.9 \pm 1.3$ \\
\hline $\mathbf{Y}_{\text {ButOH/S }}\left(\mathrm{mg}_{\mathrm{ButOH}} \cdot \mathrm{g}_{\mathrm{Gluc}}{ }^{-1}\right)$ & $9.51 \pm 0.11$ \\
\hline $\mathbf{Y}_{\text {EtOH/S }}\left(\mathrm{g}_{\text {EtOH }} \cdot \mathrm{g}_{\mathrm{Gluc}}{ }^{-1}\right)$ & $0.05 \pm 0.01$ \\
\hline $\mathbf{Y}_{\text {Succ/s }}\left(\mathrm{g}_{\text {Succ }} \cdot \mathrm{g}_{\mathrm{Gluc}}{ }^{-1}\right)$ & $0.09 \pm 0.03$ \\
\hline $\mathbf{Y}_{\text {Acet/S }}\left(\mathrm{g}_{\text {Acet }} \cdot \mathrm{g}_{\text {Gluc }}{ }^{-1}\right)$ & $0.18 \pm 0.01$ \\
\hline $\mathbf{Y}_{\text {Lact/S }}\left(\mathrm{g}_{\text {Lact }} \cdot \mathrm{g}_{\text {Gluc }}{ }^{-1}\right)$ & $0.48 \pm 0.02$ \\
\hline
\end{tabular}

$\rightarrow$ Glucose $=$ Ethanol $\rightarrow$ Succinate $\rightarrow$ Lactate $\rightarrow$ Acetate

Fig. 3 Physiological characterization of the strain OG2 in bioreactor. a Growth-curve (optical density at $600 \mathrm{~nm}$ ) profile and butanol concentration; b glucose and end-products concentrations during the fermentation and c specific growth rate $(\mu)$, duplication time $\left(t_{d}\right)$ and butanol, ethanol, succinate, acetate and lactate yields ( $Y$ ) on glucose. Cells were cultivated aerobically in HDM medium and induced with 0.5 mM of IPTG at 0.4-0.5 $\mathrm{OD}_{600}$. At this moment, anaerobic conditions were created by turning off the air flow and waiting for the leftover oxygen to be consumed. Data are shown as mean \pm SD of three independent experiments. ButOH butanol, EtOH ethanol, Succ succinate, Acet acetate, Lact lactate

to measure cell density and concentration of excreted metabolites with HPLC and GC-FID analysis. Figure 3 summarizes the obtained results.

It is possible to observe in Fig. 3 that the maximum butanol titer $\left(85 \pm 1 \mathrm{mg} \mathrm{L}^{-1}\right)$, obtained after $50 \mathrm{~h}$, represented a 1.1-fold improvement, comparing with the results obtained in serum bottles for OG2 strains (Fig. 2). We can see a biomass-product coupled behavior by analyzing the growth curve and the butanol production profile in Fig. 3a. During the first $3 \mathrm{~h}$, there is growth under aerobic conditions and at this moment, $0.5 \mathrm{mM}$ of IPTG was added to the medium. Between 5 and $12 \mathrm{~h}$, the growth rate and glucose consumption decreased. The switch to anaerobic conditions and the metabolic burden imposed by IPTG induction can explain this deceleration. Next, between 12 and 50 h, cells continuously grew, consuming glucose, producing butanol and mixed-acid fermentation products until reaching a stationary phase.

Butanol was first detected at $24 \mathrm{~h}$ of fermentation and its accumulation increased until $50 \mathrm{~h}$. For this moment on, butanol concentration remained constant, coinciding with the glucose exhaustion and biomass growth plateau. In the experiments using serum bottles (Fig. 2), the greatest titer was only achieved after $96 \mathrm{~h}$ of cell growth. So, we can conclude that cultivating the cells under controlled conditions has accelerated butanol production, although the increment on titers has been modest. Nevertheless, even in bioreactors, the growth rate $(\mu)$ was low $\left(0.035 \pm 0.002 \mathrm{~h}^{-1}\right)$, representing a duplication time of $19.9 \pm 1.3 \mathrm{~h}$. Analyzing Fig. $3 \mathrm{~b}$, lactate was the major fermentation product released by the cells. In fact, the yield of lactate on glucose was $0.48 \pm 0.02 g_{\text {Lac }} g_{\text {gluc }}^{-1}$. Butanol yield on substrate was the lowest one within the detected products, namely succinate, ethanol, lactate and acetate. So, during the anaerobic growth, E. coli preferably uses the native pathways to recycle the excess of NADH instead of the butanol pathway, even with the high amount of heterologous proteins being presumably expressed. This was also observed by other groups expressing the clostridial pathway in E. coli, in which 
butanol accumulation increased after deleting mixedacid fermentation pathways $[5,28]$.

\section{Discussion}

The main objective of this study was to rationally design a new microbial cell factory able to produce butanol through a novel pathway, generated by a hypergraph algorithm. Furthermore, the analysis carried using several in silico tools aimed to save time in the lab by avoiding a trial and error experimental approach.

From the initial set of 105,954 different pathways, only 40,608 routes could actually produce butanol when integrated into an E. coli model. Since stoichiometry is not considered by the enumeration algorithm, the FBA simulations allowed to identify the stoichiometrically feasible pathways, i.e., with butanol flux. The successive filters applied (based on size and novelty) allowed the identification of a set of 24 pathways. These pathways catalyze, with some alternative reactions, the conversion of 2-oxoglutarate into $n$-butanol. Within $E$. coli and maximizing butanol production in silico under anaerobic conditions, $\mathrm{NADH}$ would be the most efficient cofactor to produce butanol using this pathway. By retrieving the literature and analyzing databases, we selected the most suitable enzymes for the different steps of this pathway. The in vivo implementation of this pathway allowed butanol production when the fourth step was catalyzed by glutaryl-CoA dehydrogenase (OG1 and OG2) expressed in pRSFDuet, but not when the $\alpha$-subunit of the glutaconylCoA decarboxylase was used in its place (OG3 and OG4) using an expression vector with a lower copy numberpCOLADuet. To the best of our knowledge, this was the first time that butanol was produced in $E$. coli through this pathway using $2 \mathrm{OG}$ as precursor.

Escherichia coli K12 MG1655 was used as host for expressing the 2OG pathway, considering that all the in silico simulations were based on $i \mathrm{JO} 1366$ [39], a genomescale metabolic model developed for this strain. We also tested E. coli BL21 (DE3) to produce butanol for being considered more suitable for heterologous gene expression. In fact, $E$. coli genome had been modified in BL21 (DE3) to improve protein expression, lacking genes encoding proteases (such as Lon and $O m p T$ ) and preventing plasmid loss by the mutation in gene $h s d B$ [40]. Nevertheless, the results (Figs. 2, 3) showed that E. coli K12 produced higher titers of butanol through the $2 \mathrm{OG}$ pathway than the BL21 equivalent. Since recombinant protein production is expected to be favored in BL21 hosts, a possible explanation for the results may be the metabolism of the two different strains. Reportedly, in BL21 cells, the enzymes responsible for the glyoxylate bypass are constitutively expressed; while in K12 cells, their expression is extremely regulated [41]. This pathway converts directly isocitrate and acetyl-CoA into malate and succinate, avoiding the two successive decarboxylations of isocitrate into 2OG and succinyl-CoA [41]. Assuming that the glyoxylate bypass is only active in OG1 strains when glucose is the main carbon source, the respective flux through the oxidative branch of the TCA cycle will be lower than in OG2. Consequently, the accumulation of $2 \mathrm{OG}$ will be reduced [42]. So, we hypothesize that, in OG2 strains, the $2 \mathrm{OG}$ pool is higher, increasing the flux towards the heterologous production of butanol. Moreover, the superior butanol production results when expressing the clostridial pathway in BL21-based strains (Fig. 2) support this hypothesis, since acetyl-CoA is the main precursor of the clostridial pathway. As future work, the expression of 2OG pathway into E. coli K12 JM109 hosts could provide higher butanol titers, since the genome of these K12-based strains was modified to enhance recombinant protein expression, similarly to BL21 cells [43].

It is important to point out that the major difference between the two pathways is the precursor. Both metabolites (acetyl-CoA and 2-oxoglutarate) are part of the central carbon metabolism and intermediates in fundamental biochemical pathways. The immediate advantage of the $2 \mathrm{OG}$ pathway is the thermodynamically favorable first step $\left(\Delta_{r} G^{\prime m}=-22.6 \pm 3.6 \mathrm{~kJ} \mathrm{~mol}^{-1}\right)$ to avoid the unfavorable condensation of two molecules of acetyl-CoA $\left(\Delta_{r} G^{\prime m}=26.1 \pm 1.7 \mathrm{~kJ} \mathrm{~mol}^{-1}\right)$. However, under anaerobic conditions, the TCA cycle is downregulated and $2 \mathrm{OG}$ is only synthesized to support biomass formation. The impact of draining 2-oxoglutarate from the TCA cycle has not been studied before. In the literature, there are examples of successfully expressed heterologous pathways in E. coli using 2OG as substrate for the production of glutaconate [20] and glutarate [21] under anaerobic conditions. In these works, the titers achieved are not large; so, it is not possible to infer the effect of the 2OG depletion. The simulations we performed with the novel butanol pathway showed that even when all pathways for mixed-acid fermentation are deleted (lactate, ethanol, acetate) the 2OG pathway is enough to support anaerobic growth with a reduction of the maximum growth rate to $50 \%$ of the wild type.

OG strains accumulated more butanol in the defined medium than in the complex counterpart (Fig. 2). Hence, the production of butanol seems to be positively affected by the defined HDM formulation. We hypothesize that the supplementation in HDM medium of amino acids in the free form-tryptone could contain small peptides in TB medium-positively impacts the $2 \mathrm{OG}$ pool increasing butanol accumulation. This is also supported by the data shown in Additional file 2: Fig. 
S1, where the omission of amino acids solution from HDM medium caused the highest reduction on butanol titers. The opposite results obtained with ACT strains, where TB medium provided the maximum butanol titers, agree with what is reported in the literature, where the omission of complex nutrients had a negative impact on butanol accumulation when expressing the clostridial pathway $[4,5,30,44]$. The hypotheses for this behavior include the high demand of this pathway for acetyl-CoA and NADH, limiting the available resources for protein synthesis [30] and the role of yeast extract as a nitrogen donor, increasing biomass growth and butanol titers [5].

The obtained titers are far below the industrial requirements, and thus further optimization to achieve industrial requirements is needed. Additional metabolic engineering strategies can help to develop more efficient cell factories. An obvious next step is the already mentioned deletion of the pathways for the competing fermentation products. Further exploration of strategies to improve the accumulation of the precursor 2-oxoglutarate could help to improve butanol titers obtained through the respective pathway, while the detection of pathway intermediates could allow to identify the bottleneck(s), providing insight for the next steps for strain engineering [28].

Other strategies include the use of RBS strength prediction algorithms or manipulation of mRNA stability [45] to fine-tune gene expression [46]. Also, application of techniques such as transcriptomics, fluxomics and metabolomics could give insight on the metabolism of the different strains, allowing to identify possible metabolic engineering strategies to increase butanol accumulation [47].

\section{Conclusions}

In this work, we were able to design novel strains of $E$. coli capable of producing butanol through a novel pathway generated by a hypergraph algorithm using 2-oxoglutarate as the precursor.

Escherichia coli OG2, using E. coli K12 MG1655 DE3 as host, provided higher final titers of butanol than using BL21. The greatest titer $\left(75 \pm 4 \mathrm{mg} \mathrm{L}^{-1}\right)$ was obtained by cultivating OG2 strains in HDM medium and inducing with $0.5 \mathrm{mM}$ of IPTG.

The maximum titers obtained for this novel pathway are still far below from those required for industrial purposes. The results obtained in the bioreactor indicate that the cells expressing $2 \mathrm{OG}$ pathway preferably recycle $\mathrm{NADH}$ using native mixed-acid fermentation pathways instead of the heterologous pathway. The knock-out of mixed-acid fermentation pathways probably is necessary to force NADH recycling using the heterologous pathway. These metabolic engineering strategies were coupled with other approaches to increment the 2OG availability and are ongoing.

\section{Materials and methods In silico analysis of heterologous pathways}

Several alternative routes to produce $n$-butanol were generated using an hypergraph algorithm previously developed within our group [13] based on FindPath (FP) [48] using a proprietary database as the search space. The aim was to enumerate all possible combinations of reactions leading from any reaction at the central carbon metabolism of Escherichia coli to n-butanol. The solutions obtained were analyzed to select the most promising ones to implement in vivo. The first step of this analytical process was to test if the pathways would allow butanol production when inserted in the $i$ JO1366 E. coli GSMM [39]. This test was carried using FBA (flux balance analysis) with maximization of butanol flux as the objective function, for each pathway generated. Since stoichiometry is not considered by the enumeration algorithm, the FBA simulations without butanol production (i.e., maximum butanol flux $=0$ ) allowed to identify the stoichiometrically infeasible pathways. Pathways without any butanol flux were discarded and diverse filters were successively applied to the remaining pathways. First, the pathways were sorted by size, i.e., the number of reactions needed to catalyze the initial precursor into butanol. Since clostridial pathway is constituted by six steps, the maximum threshold for pathway size was set to seven. Within the diverse groups sorted by size, the pathways were ranked accordingly to the conservation of number of carbon atoms (i.e., the difference between the number of carbons of the initial substrate and butanol). For the pathways with the greatest conservation of carbon atoms, a manual analysis was carried out.

To assure the novelty of the chosen pathways, the relevant literature was searched for any previous reports of butanol production using the same set of reactions and the ones already reported were discarded. Then, the availability of curated gene sequences encoding the enzymes that catalyze the different reactions was verified by consulting databases such as UniProt [49], KEGG [1416], and MetaCyc [50]. For all the reactions constituting the most promising set of pathways, the change in Gibbs free energy $\left(\Delta_{r} G^{\prime m}\right)$ and Equilibrium constant $\left(K_{\text {eq }}^{\prime}\right)$ were calculated using eQuilibrator 2.0 [17] to evaluate their reversibility. These values were estimated using Component Contribution [51] considering reactants concentrations of $1 \mathrm{mM}$, a pH of 7 and an ionic strength of $0.1 \mathrm{M}$. 


\section{Genome-scale model and software}

The reactions constituting the most promising pathway obtained from the analysis described in the previous section were again added to iJO1366 E. coli GSMM [39]. Additional file 3: Table S2 shows the stoichiometry of the reactions added to the model, as well as transport reaction to allow the excretion of butanol. Reaction R01175 was not added to the GSMM, since the model already includes this reaction (R_ACOAD1f). The reaction $(S)$ 3-hydroxybutanoyl-CoA hydrolyase (R_ECOAH1) was deleted from the GSMM to make sure that butanol production originated from the heterologous pathway.

OptFlux3 [52] and FBA were used to perform all in silico analyses. $n$-Butanol production was studied under anaerobic (oxygen uptake flux was set to $\left.0 \mathrm{mmol}\left(\mathrm{g}_{\mathrm{DW}} \mathrm{h}\right)^{-1}\right)$ environmental conditions, with the glucose uptake rate set to $10 \mathrm{mmol}\left(\mathrm{g}_{\mathrm{DW}} \mathrm{h}\right)^{-1}$ and ammonia, phosphate and sulfate uptake unconstrained and using butanol export reaction as the objective function. Flux variability analysis (FVA) allowed to infer the robustness of butanol production, i.e., to determine the flux limits of the active reactions under anaerobic conditions.

\section{Strains and plasmids}

The strains and plasmids used or constructed in this study as well as all the primers used are listed in Additional file 4: Tables S3, S4 and S5.

\section{Cloning procedure}

Basic molecular biology techniques were employed as previously described [53]. The genes used in this study were amplified by polymerase chain reaction (PCR) using Phusion High-Fidelity DNA Polymerase (Thermo Scientific, Waltham, USA) in a LifeECO Thermal Cycler (Bioer Technology, Zhejiang, China). All primers were purchased from Metabion (Munich, Germany). DNA fragments were purified using DNA Clean and Concentrator DNA Kit (Zymo Research, Irvine, USA).

Plasmids were extracted using Plasmid Miniprep kit (Zymo Research). All digestions were performed using the appropriate FastDigest ${ }^{\circledR}$ restriction endonucleases (Thermo Scientific). Ligations were performed with T4 DNA Ligase (Thermo Scientific) and transformed by heat-shock in chemically competent $E$. coli NEB 5-alpha cells (New England BioLabs, Massachusetts, USA). The success of ligation was checked through Colony PCR using DreamTaq (Thermo Scientific) and further confirmed by sequencing (StabVida, Lisbon, Portugal). Protocols were performed in accordance with manufacturer's instructions.
Shake flasks and sealed flasks experiments

Butanol production experiments were performed in Terrific Broth (TB) medium [54] and high-density medium (HDM) adapted from [55].

TB medium contained, per liter, tryptone (12 g); yeast extract $(24 \mathrm{~g})$; glycerol $(4 \mathrm{~mL})$; monobasic potassium phosphate $(2.31 \mathrm{~g})$ and dibasic potassium phosphate $(12.54 \mathrm{~g})$. The $\mathrm{pH}$ of this medium was $7.2 \pm 0.2$ at $25^{\circ} \mathrm{C}$; adjustments were not necessary.

HDM formulation contained (per liter) dibasic sodium phosphate dihydrate $(8.89 \mathrm{~g})$; monobasic potassium phosphate $(6.8 \mathrm{~g})$; sodium chloride $(0.58 \mathrm{~g})$; magnesium sulphate (1.35 g); calcium chloride dihydrate $(0.038 \mathrm{~g})$; ammonium chloride $(1 \mathrm{~g})$; trace metals $(250 \mu \mathrm{L})$; vitamins BME $100 \times(250 \mu \mathrm{L})$ and an amino acid mix (2 g).

The trace metals solution contained (per liter): $\mathrm{FeSO}_{4} \cdot 7 \mathrm{H}_{2} \mathrm{O}(30 \mathrm{mg}) ; \mathrm{ZnSO}_{4} \cdot 7 \mathrm{H}_{2} \mathrm{O}(45 \mathrm{mg}) ; \mathrm{CaCl}_{2} \cdot 2 \mathrm{H}_{2} \mathrm{O}$ (45 mg); $\mathrm{MnCl}_{2} \cdot 2 \mathrm{H}_{2} \mathrm{O}$ (100 mg); $\mathrm{CoCl}_{2} \cdot 6 \mathrm{H}_{2} \mathrm{O}$ (30 mg); $\mathrm{CuSO}_{4} \cdot 5 \mathrm{H}_{2} \mathrm{O}(30 \mathrm{mg}) ; \mathrm{Na}_{2} \mathrm{MoO}_{4} \cdot 2 \mathrm{H}_{2} \mathrm{O}(40 \mathrm{mg}) ; \mathrm{H}_{3} \mathrm{BO}_{3}$ $(10 \mathrm{mg})$; KI $(10 \mathrm{mg})$ and $\mathrm{Na}_{2}$ EDTA $(1.5 \mathrm{~g})$. The amino acid mix contained $1 \mathrm{~g}$ of adenine and $4 \mathrm{~g}$ of arginine, aspartate, glutamate, histidine, isoleucine, lysine, methionine, phenylalanine, serine, threonine, tryptophan, tyrosine and valine. The vitamin BME $100 \times$ solution (Sigma Aldrich, St. Louis, MO, USA) contained (per liter): D-biotin $(0.1 \mathrm{~g})$; choline chloride $(0.1 \mathrm{~g})$; folic acid $(0.1 \mathrm{~g})$; myoinositol (0.2 g); niacinamide (0.1 g); D-pantothenic acid. $1 / 2 \mathrm{Ca}(0.1 \mathrm{~g})$; riboflavin $(0.01 \mathrm{~g})$; thiamine $\mathrm{HCl}(0.1 \mathrm{~g})$ and $\mathrm{NaCl}(8.5 \mathrm{~g})$. The $\mathrm{pH}$ of the medium was adjusted to 7.1 at $25^{\circ} \mathrm{C}$ using $2 \mathrm{M} \mathrm{NaOH}$.

For strains expressing $2 \mathrm{OG}$ pathway, both media were supplemented, per liter, with $10 \mathrm{~g}$ glucose; 0.468 g glutamate; $0.0753 \mathrm{~g}$ riboflavin and $0.525 \mathrm{~g}$ iron (III) citrate.

Luria-Bertani (LB) medium contained $10 \mathrm{~g} \mathrm{~L}^{-1}$ of peptone; $5 \mathrm{~g} \mathrm{~L}^{-1}$ yeast extract and $5 \mathrm{~g} \mathrm{~L}^{-1}$ of $\mathrm{NaCl}$. The solid version of this medium included $15 \mathrm{~g} \mathrm{~L}^{-1}$ agar.

All cultivations were performed with the addition of suitable antibiotics according to the employed plasmids. For OG and ACT strains, the antibiotics concentrations

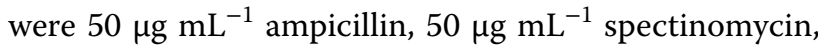
and $30 \mu \mathrm{g} \mathrm{mL}{ }^{-1}$ kanamycin. For control strains, the concentrations employed were $50 \mu \mathrm{g} \mathrm{mL}^{-1}$ ampicillin and $30 \mu \mathrm{g} \mathrm{mL}^{-1}$ kanamycin.

A single colony was picked from LB plates and inoculated in $10 \mathrm{~mL}$ of liquid LB medium. The pre-cultures were grown aerobically on a rotary shaker at $37{ }^{\circ} \mathrm{C}$ and 200 rpm, overnight.

In HDM experiments, an appropriate volume of cells was harvested from the pre-culture by centrifugation $(10 \mathrm{~min}$ at $3000 \times \mathrm{g}$ ) and washed with HDM medium and then transferred to $500-\mathrm{mL}$ shake flasks with $100 \mathrm{~mL}$ of medium, yielding an initial $\mathrm{OD}_{600}$ of 0.1 . In $\mathrm{TB}$ experiments, an appropriate volume of pre-culture was 
directly transferred to $500-\mathrm{mL}$ shake flasks with $100 \mathrm{~mL}$ of medium, yielding an initial $\mathrm{OD}_{600}$ of 0.1 . These cultures were also cultivated on a rotary shaker at $200 \mathrm{rpm}$ at $37{ }^{\circ} \mathrm{C}$. Butanol production genes were induced with $0.5 \mathrm{mM}$ IPTG at an $\mathrm{OD}_{600}$ of 0.4-0.5.

To promote butanol production, after induction, the cells were switched to anaerobic conditions by transferring $60 \mathrm{~mL}$ of culture to $120-\mathrm{mL}$ sealed serum flasks. The culture was supplemented with $600 \mu \mathrm{L}$ of a $0.01 \mathrm{M}$ stock solution of sodium bicarbonate to achieve a final concentration of $10 \mathrm{mM}$, since it reduces long lag phases in E. coli anaerobic growth [56]. $60 \mu \mathrm{L}$ of a solution of extra trace metals $\left[\mathrm{NiCl}_{2}\left(1.7 \mathrm{mg} \mathrm{L}^{-1}\right) ;\left(\mathrm{NH}_{4}\right)_{6} \mathrm{Mo}_{7} \mathrm{O}_{24}\left(14.5 \mathrm{mg} \mathrm{L}^{-1}\right)\right.$; $\left.4 \mathrm{H}_{2} \mathrm{O} \mathrm{Na}_{2} \mathrm{SeO}_{3}\left(2.4 \mathrm{mg} \mathrm{L}^{-1}\right)\right]$ was supplied to the medium since selenium, nickel and molybdenum are part of the formate hydrogen lyase (FHL) complex, which is induced under anaerobic conditions [57]. After induction, the cultures were incubated at $30^{\circ} \mathrm{C}$ and $180 \mathrm{rpm}$, for $96 \mathrm{~h}$.

Samples of broth were collected at time 0, induction time and $96 \mathrm{~h}$ for $\mathrm{OD}_{600}$ measurements and high-performance liquid chromatography (HPLC) and gas chromatography-flame ionization detector (GC-FID) analysis of the supernatant. All experiments were performed in triplicate.

\section{Bioreactor cultivations}

Bioreactor fermentations were performed in HDM medium. Cells were pre-grown overnight in $500-\mathrm{mL}$ shake flasks containing $100 \mathrm{~mL}$ of the same medium, at $37^{\circ} \mathrm{C}$ and $200 \mathrm{rpm}$. Each fermenter was inoculated at an initial $\mathrm{OD}_{600}$ of 0.15 . The fermentations were performed in the Eppendorf DASGIP Parallel Bioreactor System (Switzerland) using 2-L culture vessels. The operating volume for the fermentations was $0.5 \mathrm{~L}$, temperature was maintained at $37^{\circ} \mathrm{C}$, airflow at $1 \mathrm{VVM}, \mathrm{pH}$ was kept at 7.0 controlled by addition of $2 \mathrm{M} \mathrm{NaOH}$, and dissolved oxygen was kept above $30 \%$ of saturation by feedback control of the stirring speed from $200 \mathrm{rpm}$ up to $400 \mathrm{rpm}$. Expression of the butanol genes was induced with $0.5 \mathrm{mM}$ of IPTG when an $\mathrm{OD}_{600}$ of 0.4-0.5 was reached. After IPTG induction, temperature was decreased to $30^{\circ} \mathrm{C}$ and stirring speed to $180 \mathrm{rpm}$. Anaerobic conditions were created by turning off the air flow and waiting for the leftover oxygen to be consumed. Samples were taken every $2 \mathrm{~h}$ for the first $12 \mathrm{~h}$ of the fermentation and, then, every $12 \mathrm{~h}$. At each time point, the optical density was measured, and the supernatant was analyzed by HPLC and GC-FID.

\section{Analytical methods}

Butanol was quantified by GC and organic acids, ethanol and glucose by HPLC.
Samples were centrifuged at $6000 \times g$ for $10 \mathrm{~min}$ to separate cells from the medium. Afterwards, the supernatant was filtered with a $0.22 \mu \mathrm{m}$ pore filter membrane to glass vials and stored at $-20{ }^{\circ} \mathrm{C}$ until analyzed.

Quantitative analysis of organic acids and glucose was performed using a HPLC apparatus from Jasco (Japan) model LC-NetII/ADC equipped with UV-2075 Plus and RI-4030 Plus detectors, also from Jasco. The samples were analyzed using an Aminex HPX-87H column $(300 \mathrm{~mm} \times 7.7 \mathrm{~mm})$ from Bio-Rad, which was kept at $60{ }^{\circ} \mathrm{C}$, and $5 \mathrm{mmol} \mathrm{L}^{-1} \mathrm{H}_{2} \mathrm{SO}_{4}$ was used as mobile phase

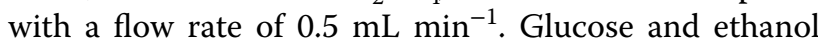
were detected with the refractive index (RI) detector and organic acids (succinate, lactate, formate and acetate) were detected at $210 \mathrm{~nm}$ using the UV detector. Calibration curves were obtained by injecting standards with known concentrations for each metabolite. Metabolite concentrations in samples were calculated by comparing the peak areas of the samples with the calibration curves.

Butanol concentration was quantified by a GP-9000 system (Chrompack) with a Meta-WAX capillary column $(30 \mathrm{~m} \times 0.25 \mathrm{~mm} \times 0.25 \mu \mathrm{m})$ equipped with a flame ionization detector (FID) where Helium was used as carrier gas with a flow rate of $1 \mathrm{~mL} \mathrm{~min}{ }^{-1}$. The filtered supernatant $(900 \mu \mathrm{L})$ was mixed with $100 \mu \mathrm{L}$ of a $5 \mathrm{~g} \mathrm{~L}^{-1}$ solution of isobutanol, the internal standard, yielding a final concentration of $0.5 \mathrm{~g} \mathrm{~L}^{-1}$, and $1 \mu \mathrm{L}$ of this mixture was injected. The temperatures of injector and detector were maintained at $250{ }^{\circ} \mathrm{C}$. The column temperature was initially at $50{ }^{\circ} \mathrm{C}$, heated to $177.5^{\circ}$ $\mathrm{C}$ at a $5{ }^{\circ} \mathrm{C} \mathrm{min}^{-1}$ rate and then heated to $230{ }^{\circ} \mathrm{C}$ at $10{ }^{\circ} \mathrm{C} \mathrm{min}{ }^{-1}$, which was held for $15 \mathrm{~min}$. A calibration curve was obtained by injecting standards with several concentrations of butanol and a fixed concentration of internal standard (0.5 g L $\mathrm{L}^{-1}$ of isobutanol). Butanol concentration was calculated by comparing the ratio between its peak area and internal standard peak area with calibration curves.

All optical density measurements at $600 \mathrm{~nm}\left(\mathrm{OD}_{600}\right)$ were performed using the spectrophotometer Ultrospec 10 from Biochrom (Cambridge, UK).

\section{Supplementary information}

Supplementary information accompanies this paper at https://doi. org/10.1186/s13068-019-1565-X.

Additional file 1: Table S1. Simulation results using flux balance analysis and flux variability analysis.

Additional file 2: Fig. S1. Medium formulation influence on butanol accumulation.

Additional file 3: Table S2. Reactions added to Escherichia coli genome scale metabolic model iJO1366. 
Additional file 4: Table S3. Sequences of primers used in the cloning procedures of this study; Table S4. List of plasmids used or designed in this study. Table S5. List of strains and genomic DNA used or engineered for this study.

\section{Abbreviations}

2OG: 2-oxoglutarate; 2-HdxG: 2-hydroxyg lutarate; HdxG-CoA: 2-hydroxyglutaryl-CoA; 3-HB-COA: 3-hydroxybutyryl-COA; ABE: acetone-butanol-ethanol; AcAcCoA: acetoacetyl-CoA; acCoA: acetyl-CoA; Acet: acetate; AF: Acidaminococcus fermentans; But-CoA: butanoyl-CoA; ButOH: butanol; CA: Clostridium acetobutylicum; Cit: citrate; Crt-CoA: crotonyl-CoA; CS: Clostridium symbiosum EC: enzyme commission; EtOH: ethanol; Exp: experimental; FBA: flux balance analysis; FID: flame ionization detector; FP: FindPath; FVA: flux variability analysis; GC: gas chromatography; GSMM: genome-scale metabolic model; GtcCoA: glutaconyl-CoA; HDM: high-density medium; HPLC: high-performance liquid chromatography; IPTG: isopropyl $\beta$-1-thiogalactopyranoside; KEGG: Kyoto Encyclopedia of Genes and Genomes; Lact: lactate; LB: Luria Bertani; ME: metabolic engineering; $\mathrm{OAA}$ : oxaloacetate; $\mathrm{OD}_{600}$ : optical density at $\lambda_{600} \mathrm{~nm}$; PA: Pseudomonas aeruginosa; PCR: polymerase chain reaction; PEP: phosphoenolpyruvate; RI: refractive index; Succ: succinate; TCA: tri-carboxylic acid; TB: Terrific Broth; TD: Treponema denticola; UV: ultraviolet.

\section{Authors' contributions}

IR designed the project. FL and PV were involved in all the in silico analysis. SF and RP designed and performed all the experiments and data analysis, supervised by IR. SF, RP and IR wrote the paper, and all the authors checked thoroughly the manuscript. All authors read and approved the final manuscript.

\section{Funding and acknowledgments}

This study was supported by the Portuguese Foundation for Science and Technology (FCT) under the scope of a Ph.D. Grant (PD/BD/52366/2013) from MIT Portugal Program and the strategic funding of UID/BIO/04469 unit. Additional support was received by COMPETE 2020 (POCl-01-0145-FEDER-006684) and BioTecNorte operation (NORTE-01-0145-FEDER-000004) funded by the European Regional Development Fund under the scope of Norte2020-Programa Operacional Regional do Norte.

The authors also thank the Times New Roman project "Dynamics", Ref. ERAIB-2/0002/2014, funded by national funds through FCT/MCTES. The genes thl, hbd, crt and adhE1 were kindly provided by Kristala L. Jones Prather from MIT.

The authors thank the project DDDeCaF - Bioinformatics Services for Data-Driven Design of Cell Factories and Communities, Ref. H2020-LEITBIO-2015-1 686070-1, funded by the European Commission and the Project LISBOA010145FEDER007660 (Microbiologia Molecular, Estrutural e Celular) funded by FEDER funds through COMPETE2020 Programa Operacional Competitividade e Internacionalização (POCI) and by national funds through FCT Fundacao para a Ciencia e a Tecnologia.

\section{Availability of data and materials}

The datasets used and/or analyzed during the current study are available from the corresponding author on reasonable request.

\section{Ethics approval and consent to participate}

Not applicable.

\section{Consent for publication}

Not applicable.

\section{Competing interests}

The authors recently applied as inventors of a patent application related to the content of the manuscript. In any way the authors, or whatever organization, will gain or lose financially from the publication of this manuscript, either now nor in the future.

\section{Author details}

${ }^{1}$ CEB-Centre of Biological Engineering, University of Minho, Campus de Gualtar, 4710-057 Braga, Portugal. ${ }^{2}$ SilicoLife Lda, Rua do Canastreiro 15, 4715-387 Braga, Portugal. ${ }^{3}$ Present Address: Department of Biology and Biological Engineering, Chalmers University of Technology, 41296 Gothenburg,
Sweden. ${ }^{4}$ Present Address: Mathematics and Computer Science Division, Argonne National Laboratory, Argonne, IL, USA. ${ }^{5}$ Instituto de Tecnologia Química e Biológica António Xavier, Universidade Nova de Lisboa (ITQBNOVA), Oeiras, Portugal.

Received: 17 January 2019 Accepted: 7 September 2019 Published online: 30 September 2019

\section{References}

1. Koppolu V, Vasigala VK. Role of Escherichia coli in Biofuel Production. Microbiol insights. 2016;14(9):29-35.

2. Amador-Noguez D, Brasg IA, Feng X-J, Roquet N, Rabinowitz JD. Metabolome remodeling during the acidogenic-solventogenic transition in Clostridium acetobutylicum. Appl Environ Microbiol. 2011;77(22):7984-97.

3. Gheshlaghi R, Scharer JM, Moo-Young M, Chou CP. Metabolic pathways of clostridia for producing butanol. Biotechnol Adv. 2009;27(6):764-81.

4. Atsumi S, Cann AF, Connor MR, Shen CR, Smith KM, Brynildsen MP, et al. Metabolic engineering of Escherichia coli for 1-butanol production. Metab Eng. 2008;10(6):305-11.

5. Shen CR, Lan El, Dekishima Y, Baez A, Cho KM, Liao JC. Driving forces enable high-titer anaerobic 1-butanol synthesis in Escherichia coli. Appl Environ Microbiol. 2011;77(9):2905-15.

6. Zheng YN, Li LZ, Xian M, Ma YJ, Yang JM, Xu X, et al. Problems with the microbial production of butanol. J Ind Microbiol Biotechnol. 2009;36(9):1127-38.

7. Garza E, Zhao J, Wang Y, Wang J, Iverson A, Manow R, et al. Engineering a homobutanol fermentation pathway in Escherichia coli EG03. J Ind Microbiol Biotechnol. 2012;39(8):1101-7.

8. Chan W, Mohamad M, Deris S, Illias R. A review of computational approaches for In silico metabolic engineering for microbial fuel production. Curr Bioinform. 2013;8(2):253-8.

9. Shen CR, Liao JC. Metabolic engineering of Escherichia coli for 1-butanol and 1-propanol production via the keto-acid pathways. Metab Eng. 2008;10(6):312-20.

10. Dellomonaco C, Clomburg JM, Miller EN, Gonzalez R. Engineered reversal of the $\beta$-oxidation cycle for the synthesis of fuels and chemicals. Nature. 2011;476(7360):355-9.

11. Gulevich AY, Skorokhodova AY, Sukhozhenko AV, Shakulov RS, Debabov VG. Metabolic engineering of Escherichia coli for 1-butanol biosynthesis through the inverted aerobic fatty acid $\beta$-oxidation pathway. Biotechnol Lett. 2012;34(3):463-9.

12. Lan El, Liao JC. ATP drives direct photosynthetic production of 1-butanol in cyanobacteria. PNAS. 2012;109(16):6018-23.

13. Liu F, Vilaça P, Rocha I, Rocha M. Development and application of efficient pathway enumeration algorithms for metabolic engineering applications. Comput Methods Programs Biomed. 2015;118(2):134-46.

14. Kanehisa M, Furumichi M, Tanabe M, Sato Y, Morishima K. KEGG: new perspectives on genomes, pathways, diseases and drugs. Nucleic Acids Res. 2017;45(D1):D353-61.

15. Kanehisa M, Goto S. KEGG: Kyoto encyclopedia of genes and genomes. Nucleic Acids Res. 2000;28(1):27-30.

16. Kanehisa M, Sato Y, Kawashima M, Furumichi M, Tanabe M. KEGG as a reference resource for gene and protein annotation. Nucleic Acids Res. 2016;44(D1):D457-62.

17. Flamholz A, Noor E, Bar-Even A, Milo R. EQuilibrator-the biochemical thermodynamics calculator. Nucleic Acids Res. 2012;40(D1):770-5.

18. Bar-Even A, Flamholz A, Noor E, Milo R. Thermodynamic constraints shape the structure of carbon fixation pathways. Biochim Biophys Acta Bioenerg. 2012;1817(9):1646-59.

19. Lerud RF, Whiteley HR. Purification and properties of a-ketoglutarate reductase from Micrococcus aerogenes. J Bacteriol. 1971;106(2):571-7.

20. Djurdjevic I, Zelder O, Buckel W. Production of glutaconic acid in a recombinant Escherichia coli strain. Appl Environ Microbiol. 2011;77(1):320-2.

21. Yu J-L, Xia X-X, Zhong J-J, Qian Z-G. A novel synthetic pathway for glutarate production in recombinant Escherichia coli. Process Biochem. 2017;59(May):167-71.

22. Buckel W, Dorn U, Semmler R. Glutaconate CoA-transferase from Acidaminococcus fermentans. Eur J Biochem. 1981;118(2):315-21. 
23. Hans M, Sievers Ė, Mu U, Bill E, Vorholt JA, Linder D, et al. 2-Hydroxyglutaryl-CoA dehydratase from Clostridium symbiosum. Eur J Biochem. 1999:414:404-14.

24. Schweiger G, Dutscho R, Buckel W. Purification of 2-hydroxyglutarylCoA dehydratase from Acidaminococcus fermentans. Eur J Biochem. 1987;169(2):441-8.

25. Härtel U, Eckel E, Koch J, Fuchs G, Linder D, Buckel W. Purification of glutaryl-CoA dehydrogenase from Pseudomonas sp., an enzyme involved in the anaerobic degradation of benzoate. Arch Microbiol. 1993;159(2):174-81.

26. Kress D, Brügel D, Schall I, Linder D, Buckel W, Essen L-O. An asymmetric model for $\mathrm{Na}^{+}$-translocating glutaconyl-CoA decarboxylases. J Biol Chem. 2009:284(41):28401-9.

27. Hu K, Zhao M, Zhang T, Zha M, Zhong C, Jiang Y, et al. Structures of trans2-enoyl-CoA reductases from Clostridium acetobutylicum and Treponema denticola: insights into the substrate specificity and the catalytic mechanism. Biochem J. 2013;89:79-89.

28. Ohtake T, Pontrelli S, Laviña WA, Liao JC, Putri SP. Metabolomics-driven approach to solving a CoA imbalance for improved 1-butanol production in Escherichia coli. Metab Eng. 2017:41:135-43.

29. Bokinsky G, Peralta-yahya PP, George A, Holmes BM, Steen EJ, Dietrich J. Synthesis of three advanced biofuels from ionic liquid-pretreated switchgrass using engineered Escherichia coli. PNAS. 2011;108(50):19949-54.

30. Wen RC, Shen CR. Self-regulated 1-butanol production in Escherichia coli based on the endogenous fermentative control. Biotechnol Biofuels. 2016;9:1-15.

31. Fontaine L, Meynial-salles I, Girbal L, Yang X, Croux C, Soucaille P. Molecular characterization and transcriptional analysis of $a d h E 2$, the gene encoding the NADH-dependent aldehyde/alcohol dehydrogenase responsible for butanol production in alcohologenic cultures of Clostridium acetobutylicum ATCC 824. J Bacteriol. 2002:184(3):821-30.

32. Nielsen DR, Leonard E, Yoon S-H, Tseng H-C, Yuan C, Prather KLJ. Engineering alternative butanol production platforms in heterologous bacteria. Metab Eng. 2009;11(4):262-73.

33. Inui M, Suda M, Kimura S, Yasuda K, Suzuki H, Toda H, et al. Expression of Clostridium acetobutylicum butanol synthetic genes in Escherichia coli. Appl Microbiol Biotechnol. 2008;77(6):1305-16.

34. Buckel W, Barker HA. Two pathways of glutamate fermentation by anaerobic bacteria. J Bacteriol. 1974;117(3):1248-60.

35. Dong H, Zhao C, Zhang T, Lin Z, Li Y, Zhang Y. Engineering Escherichia coli cell factories for n-butanol production. In: Ye Q, Bao J, Zhong J-J, editors. Bioreactor engineering research and industrial applications I: cell factories. Berlin: Springer; 2016. p. 141-63.

36. Blázquez B, Carmona M, García JL, Díaz E. Identification and analysis of a glutaryl-CoA dehydrogenase-encoding gene and its cognate transcriptional regulator from Azoarcus sp. CIB Environ Microbiol. 2008;10(2):474-82.

37. Chang Y-J, Pukall R, Saunders E, Lapidus A, Copeland A, Nolan M, et al. Complete genome sequence of Acidaminococcus fermentans type strain (VR4). Stand Genomic Sci. 2010;3(1):1-14.

38. Braune A, Bendrat K, Rospert S, Buckel W. The sodium ion translocating glutaconyl-CoA decarboxylase from Acidaminococcus fermentans: cloning and function of the genes forming a second operon. Mol Microbiol. 1999;31(2):473-87.

39. Orth JD, Conrad TM, Na J, Lerman JA, Nam H, Feist AM, et al. A comprehensive genome-scale reconstruction of Escherichia coli metabolism-2011. Mol Syst Biol. 2011;7:535.

40. Rosano GL, Ceccarelli EA. Recombinant protein expression in Escherichia coli: advances and challenges. Front Microbiol. 2014;5:1-17.

41. Phue JN, Shiloach J. Transcription levels of key metabolic genes are the cause for different glucose utilization pathways in E. coli B (BL21) and E. coli K (JM109). J Biotechnol. 2004;109(1-2):21-30.
42. Li N, Zhang B, Chen T, Wang Z, Tang YJ, Zhao X. Directed pathway evolution of the glyoxylate shunt in Escherichia coli for improved aerobic succinate production from glycerol. J Ind Microbiol Biotechnol. 2013:40(12):1461-75.

43. Yanisch-Perron C, Vieira J, Messing J. Improved M13 phage cloning vectors and host strains nucleotide sequences of the M13mp18 and pUC19 vectors. Gene. 1985;33(1167):103-9.

44. Bond-Watts BB, Bellerose RJ, Chang MCYY. Enzyme mechanism as a kinetic control element for designing synthetic biofuel pathways. Nat Chem Biol. 2011;7:222.

45. Carrier TA, Keasling JD. Library of synthetic $5^{\prime}$ secondary structures to manipulate mRNA stability in Escherichia coli. Biotechnol Prog. 1999:15(1):58-64.

46. Zhao C, Zhao Q, Li Y, Zhang Y. Engineering redox homeostasis to develop efficient alcohol-producing microbial cell factories. Microb Cell Fact. 2017;16:1.

47. Zhang W, Li F, Nie L. Integrating multiple "omics" analysis for microbial biology: application and methodologies. Microbiology. 2010;156(2):287-301.

48. Carbonell P, Fichera D, Pandit SB, Faulon J-L. Enumerating metabolic pathways for the production of heterologous target chemicals in chassis organisms. BMC Syst Biol. 2012;6(1):10.

49. Apweiler R, Bairoch A, Wu CH, Barker WC, Boeckmann B, Ferro S, et al. UniProt: the Universal Protein knowledgebase. Nucleic Acids Res. 2004:32(Database issue):D115-9.

50. Caspi R, Altman T, Dreher K, Fulcher CA, Subhraveti P, Keseler IM, et al. The MetaCyc database of metabolic pathways and enzymes and the BioCyc collection of pathway/genome databases. Nucleic Acids Res. 2012;40(D1):D742-53.

51. Noor E, Haraldsdóttir HS, Milo R, Fleming RMT. Consistent estimation of gibbs energy using component contributions. PLoS Comput Biol. 2013;9(7):1-11.

52. Rocha I, Maia P, Evangelista P, Vilaça P, Soares S, Pinto JP, et al. OptFlux: an open-source software platform for in silico metabolic engineering. BMC Syst Biol. 2010;4(1):45.

53. Sambrook J, Green MR. Molecular cloning: a laboratory manual. Cold Spring Harbor: Cold Spring Harbor Laboratory Press; 2001.

54. Tartoff KD, Hobbs CA. Improved media for growing plasmid and cosmid clones. Bethesda Res Labs Focus. 1987;9:12.

55. Sivashanmugam A, Murray V, Cui C, Zhang Y, Wang J, Li Q. Practical protocols for production of very high yields of recombinant proteins using Escherichia coli. Protein Sci. 2009;18(1):936-48.

56. Hornsten EG. On culturing Escherichia coli on a mineral salts medium during anaerobic conditions. Bioprocess Eng. 1995;12:157-62.

57. Soini J, Ukkonen `K, Neubauer P. High cell density media for Escherichia coli are generally designed for aerobic cultivations - consequences for large-scale bioprocesses and shake flask cultures. Microb Cell Fact. 2008;7(1):26.

\section{Publisher's Note}

Springer Nature remains neutral with regard to jurisdictional claims in published maps and institutional affiliations.

Ready to submit your research? Choose BMC and benefit from:

- fast, convenient online submission

- thorough peer review by experienced researchers in your field

- rapid publication on acceptance

- support for research data, including large and complex data types

- gold Open Access which fosters wider collaboration and increased citations

- maximum visibility for your research: over $100 \mathrm{M}$ website views per year

At BMC, research is always in progress.

Learn more biomedcentral.com/submissions 